\title{
La filosofía y la literatura entre la verdad y la mentira
}

Philosophy and literature between truth and lies

\section{Luisa Ló pez Carrascal}

Universidad Católica del N orte, Chile

E-mail: Ilopez@ucn.cl

\author{
Chuang Tzu soñó que era una mariposa y no sa- \\ bía al despertar si era un hombre quehabía soña- \\ do ser una mariposa o una mariposa que ahora \\ soñaba ser un hombre \\ Herbert Allen Giles \\ Chuang Tzu (1889)
}

L ACE un tiempo estuve en una conferencia del escritor argentino Federico Andahazi titulada "El oficio de mentir". Una de las preguntas del público condujo a Andahazi a una respuesta que me permite ahora, y a través de este ensayo, discrepar en ese punto deél. La pregunta se refería, como era de esperarse, a por qué concebía la literatura como "el oficio de mentir" y Andahazi lo explicó en relación, o mejor, en contraposición, con la filosofía. Según él, la filosofía es una ciencia, un dogma que busca la Verdad y, por el contrario, la literatura es un oficio que no busca, directa o indirectamente, otra cosa que mentir. La diferencia pareceestribar entonces entre los extremos de la ficción de la una y la "realidad" de la otra.

Para mostrar tal diferencia, Andahazi citó precisamente el prólogo (que estrictamente es la dedicatoria) de las M editaciones metafísicas de D escartes en donde dice "a los muy sabios e ilustre decano y doctores de la sagrada facultad de teología de París" que explicará por la razón lo que ellos no han podido explicar por la fe. Aunque esto no es del todo exacto, y las razones de D escartes para demostrar la existencia de D ios son muy discutidas (recuérdese el contexto histórico), lo quesí es indiscutible es que D escartes marca el inicio de la M odernidad con la exaltación de la razón (y no necesariamente en oposición a la fe).

Lo que intentaré sostener a lo largo de este escrito es que la filosofía, 0 al 
menos gran parte de ella, tiene tanto de ficción como la más maravillosa y absurda de las novelas, esto muy a pesar de los deseos eintentos de muchos filósofos. Para ello me remitiréa D escartes y a su argumento del sueño en las M editaciones metafís scas (1987) y también a Borges y su cuento "Las ruinas circulares" (1984).

\section{LA APARICION DEL GENIO MALIGNO EN UNA NOCHE DE MEDITACION}

Con frecuencia seha asociado la fil osofía a una especie de hermana menor delas ciencias, aunque originalmente el objeto de la filosofía era la astronomía, la geometría y las matemáticas. El hecho más o menos evidente de que la ciencia parece avanzar mientras la filosofía pierde terreno, es el motivo por el cual los esfuerzos de muchos filósofos, D escartes entre ellos, se han centrado en "introducir a la filosofía por el camino seguro de la ciencia", como en su momento lo expresara el mismo Kant. Pero veamos cuánto de esto consigue D escartes y cuánto hay de ficción y de absurdo en quien ha sido mil veces celebrado como el padre del racionalismo moderno.

Se dice que en una noche de invierno $D$ escartes se encontraba acuartelado en Baviera, obligándolo el clima a recluirse un tiempo en una habitación calentada por una estufa. Fue allí donde elaboró su método y, al parecer, sus M editaciones metafís $i$ cas. Se sabe que la noche del 10 de noviembre de 1619 D escartes tiene tres sueños sucesivos que interpreta como un mensaje del ciel o para consagrarse a su misión filosófica.

El punto de partida para sus reflexiones es cómo tener certeza del conocimiento, es decir, cómo distinguir lo verdadero de lo falso. D escartes se encuentra en un momento de madurez necesario para la tarea de cuestionarse acerca de la validez de lo que ha aprendido hasta ese momento, pues, según dice, y con esta frase inicia la M editación de ese día:

He advertido hace ya algún tiempo que, desde mi más temprana edad, había admitido como verdaderas muchas opiniones falsas, y que lo edificado después sobre cimientos tan poco sólidos tenía que ser por fuerza muy dudoso e incierto (1987: 43).

M ás adelante D escartes expone las causas por las que podemos dudar de todas las cosas. Tales causas corresponden a dos críticas al conocimiento sensible y dos al conocimiento racional. Por no ser el propósito de este escrito, no me detendré en cada una de ellas, así que iniciaré con la que ahora nos interesa y 
que corresponde a la imposibilidad de distinguir el sueño de la vigilia.

D escartes reflexiona del siguiente modo:

¡C uán frecuentemente me hace creer el reposo nocturno lo más trivial, como, por ejemplo, que estoy aquí, que llevo puesto un traje, que estoy sentado frente al fuego, cuando en realidad estoy echado en mi cama después de desnudarme! Pero ahora veo ese papel con los ojos abiertos, y no está adormilada esta cabeza que muevo, y conscientemente y sensiblemente extiendo mi mano, puesto que un hombre dormido no lo experimentaría con tanta claridad; como si no me acordase de que he sido ya otras veces engañado en sueños por los mismos pensamientos. Cuando doy más vueltas a la cuestión veo sin duda al guna que estar despierto no se distingue con indicio seguro del estar dormido, y me asombro de manera que el mismo estupor me confirma en la idea de que duermo (1987: 45).

D eesta manera, el argumento del sueño señala que es imposible determinar la verdad de proposiciones preceptuales como "sé que estoy sentado frente al fuego", en virtud de que en tales casos es imposible satisfacer la exigencia de saber que se está despierto. Y esto es, en consecuencia, una condición necesaria, aunque no suficiente, para saber algo del mundo circundante.

Como es sabido, el escepticismo moderno nace a partir de la exigencia cartesiana de saber si se está despierto: si yo no puedo saber que estoy despierto no sé nada del mundo que me rodea; no puedo saber, por ejemplo, que estoy sentada en esta mesa frente a un computador escribiendo acerca de la real idad... Esta constatación constituye una de las pesadillas metafísicas más famosas de la filosofía y más adelante del cine y de la literatura. Es inevitable no preguntarse ¿cómo algo tan fantástico puedesurgir dequien estaba empeñado en hacer de la filosofía una ciencia estricta? ¿Es este un argumento racional? Esto sin mencionar la introducción de un "genio maligno" en la última de sus críticas al pensamiento racional. D escartes sostiene quees posibleque exista un genio o espíritu maligno,

no menos astuto y burlador que poderoso, que ha puesto toda su industria en engañarme... que ha empleado toda su industria en engañarme; pensaría que el cielo, el aire, la tierra, los colores, las figuras, los sonidos, y todas las demás cosas exteriores no son nada más queilusiones y ensueños de que se ha servido para tender trampas a mi credibilidad; consideraría que yo mismo carezco de manos, de ojos, de carne, de sangre, que no poseo ningún sentido, pero que creo fal samente tener todas esas cosas; permanecería obstinadamente ligado a ese pensamiento, y si con ese medio no está en mi poder el llegar al conocimiento de verdad alguna, al menos sí está en mi poder el suspender mi juicio (1987: 49). 
Pero volvamos al argumento del sueño que aún hoy constituye uno de los temas predilectos de los más racionales y analíticos de los filósofos. ¿Q ué consecuencias podría traer el no poder distinguir si lo que vivo es solamente un sueño? Posiblemente el sueño de alguien más poderoso.

Estas reflexiones se entrelazan con un aspecto del pensamiento filosófico moderno, y al mismo tiempo asumen un carácter referencial para un tema de interés en el campo de la literatura, en general, y de la literatura fantástica, en particular. Es el caso deBorges, lector y amante de la filosofía, especialmente de Berkeley, Spinoza, N ietzsche y Schopenhauer.

\section{EL SOÑ AD OR SOÑ ADO}

La duda de $D$ escartes sobre la realidad se entrecruza perfectamente con la pasión de Borges en torno al ideal ismo y a estas pesadillas metafísicas en las que el sueño y la vigilia se confunden. "Las ruinas circulares" da cuenta de ello en una forma magistral de escritura de cuento corto con la que Borges se deleitaba. El protagonista del cuento es un hombre "taciturno" que venía del "Sur". D esembarca y llega a un templo en ruinas con forma circular (recuérdese el mito del eterno retorno de $\mathrm{N}$ ietzsche). Borges deja ver queallí al guna vez hubo un incendio y ahora sólo queda el color de la ceniza. El propósito que guiaba a este hombre "no era imposible, aunque sí sobrenatural. Q uería soñar un hombre: quería soñarlo con integridad minuciosa e imponerlo a la realidad" (1984: 52). Por ello "cerró los ojos pálidos y durmió, no por flaqueza de la carne sino por determinación de la voluntad". Finalmente, tras mil y una noches, el soñador sueña una criatura que duerme. Y para poder despertarla recurre al auxilio de una divinidad que, a su vez, es soñada por el propio mago "soñador". A medida que avanza el cuento, la complejidad es mayor. U na vez educado su hijo, el mago lo envía a otro templo semejante. Su condición de sueño de alguien no podía ser advertida más que por su padre y por el dios del templo. Un tiempo después dos remeros le cuentan al mago de "un hombre mágico en un templo del Norte, capaz de hollar el fuego y de no quemarse". Al final del cuento, y haciendo alusión al título, se repite la destrucción del templo por causa del fuego. El mago pensó refugiarse en las aguas, pero rápidamente entendió quela muerte venía a coronar su vejez. Así que

Caminó contra los jirones de fuego. Estos no mordieron su carne, éstos lo acariciaron y lo inundaron sin calor y sin combustión. Con alivio, con humillación, con terror, comprendió que él también era una apariencia, que otro lo estaba soñando (1984: 58). 
Precisamente el epígrafe del cuento de Borges son estas líneas de Alicia a través del espejo: "Y si él dejara de soñarte...". Recuérdese que Alicia está soñando y en su sueño escucha unos fuertes ruidos que le hicieron pensar en la posibilidad de un animal salvaje. Pero los gemelos le explican que son los ronquidos del Rey Rojo. Ellos, además, le aseguran a Alicia que no es más que una "cosa" en el sueño del Rey. ¿Q ué pasaría entonces si él dejara de soñar? Alicia no tiene existencia propia. En efecto, la realidad del mundo que está al otro lado del espejo son sólo los componentes que integran el mundo onírico del Rey. Esto se asemeja al "genio maligno" de D escartes que con sus sueños e ilusiones confunde las percepciones de los seres humanos.

Es sorprendente cómo un cuento fantástico tan bello y de tanta perfección como el de Borges haya tenido como origen la misma preocupación de quien es considerado el más racional de los filósofos.

Pero el caso de D escartes es uno en muchos. Podemos recordar a Spinoza, quien en un esfuerzo racionalista y pretendiendo decir verdades, escribela "Etica al modo geométrico", compuesta como un conjunto de definiciones, axiomas, postulados, leyes, proposiciones y escolios al modo propio de la geometría euclideana. Este maravilloso invento ha sido interpretado de muchas maneras. M iguel de Unamuno (2005) afirmó quela obra debía leerse "como lo que es: un desesperado poema elegíaco". No es deextrañar esta afirmación para quien también la filosofía y la poesía eran lo mismo:

En psicología su acción fue deletérea. H asta hubo escolásticos metidosa literatos - no digo filósofos metidos a poetas, porque poeta y filósofo son hermanos gemelos, si es que no la misma cosa- que llevaron el análisis psicológico positivista a la novela y al drama, donde hay que poner en pie hombres concretos, de carne y hueso, y en fuerza de estados de conciencia, las conciencias desaparecieron.

Por ello, pienso que el esfuerzo de hacer de la filosofía una ciencia absolutamente racional será siempre inútil en tanto quea la filosofía le pertenece desuyo aquello delo que justamente no seocupa la ciencia, es decir, de interpretaciones hipotéticas delo desconocido, como es el caso dela metafísica, o de lo conocido inexactamente, como sucede en la ética o en la filosofía política. M ientras la filosofía siga siendo lo que es, o lo queno ha podido ser, su valor estético radicará en lo que sus ideas encierran de singular, maravilloso y, por qué no, de absurdo. Ya Cicerón lo dijo hace mucho tiempo: "No hallaréis nada que sea tan absurdo que no pueda hallarse en los libros de los filósofos". 


\section{REFERENCIAS BIBLIO GRAFICAS}

Borges, Jorge Luis. 1984. "Las ruinas circulares", en Ficciones. Bogotá: Editorial La $\mathrm{O}$ veja $\mathrm{N}$ egra.

Caroll, Lewis. 1997. Alicia a través del espejo. Barcelona: Alianza.

Descartes, René. 1987. M editaciones metafísicas. M adrid: Ediciones Alba.

Spinoza, Baruch.1995. Etica. M adrid: Alianza.

Unamuno, M iguel de. 2005. D el sentimiento trágico de la vida. M adrid: Tecnos. 